\title{
FAKTOR YANG BERHUBUNGAN DENGAN POMP FILARIASIS TERHADAP PENURUNAN PREVALENSI MIKROFILARIA PASCA PENGOBATAN MASSAL TAHUN KE 5 DI KECAMATAN BUNTU BATU KABUPATEN ENREKANG
}

\section{Factors Related to Pomp Filariasis to Decrease The Prevalence of Microfilaria After The Fifth Year of Mass Treatment at The Buntu Batu of Enrekang District}

\author{
Marhtyni, Nismawati Natsir, Nur intan \\ Universitas Indonesia Timur, Makassar \\ Email : marthyninatsir@gmail.com
}

\begin{abstract}
ABSTRAK
Filariasis atau elephantiasis atau yang dalam bahasa Indonesia dikenal sebagai penyakit kaki gajah adalah penyakit yang disebabkan karena infeksi cacing filaria yang hidup di saluran limfe serta ditularkan oleh berbagai spesies nyamuk.

Jenis penelitian yang digunakan rancanganCross Sectional Study, dengan besar sampel sebanyak 257 ditentukan dengan metode proportional Random sampling yaitu mengambil secara acak dari masing-masing desa yang sudah ditentukan, di desa buntumondong 82 sampel, Desa Langda 72 sampel, desa Pasui 102 sampel. Data diperoleh dari Dinas Kesehatan.

Pengolahan data menggunakan sistem komputerisasi dengan analisis Chi-Square. Hasil uji dengan Chi-Square ditemukan bahwa faktor yang memiliki hubungan yang signifikan dengan POMP filariasis terhadap penurunan prevalensi mikrofilaria adalah pengetahuan $\left(X^{2}\right.$ hitung $(5,131)>X^{2}$ tabel $(3,841)$ atau nilai $p=(0,23)<0,05$, perilaku $\left(X^{2}\right.$ hitung $(4,046)>X^{2}$ tabel $(3,841) \quad \mathrm{p}=(0,44)<0,05$ dukungan keluarga $\left(X^{2}\right.$ hitung $(4,366) X^{2}$ tabe । $(3,841) \mathrm{p}=(0,73)<0,005$, yang tidak berhubungan adalah ketersediaan obat $X^{2}$ hitung $(1,111)>$ $X_{\text {tabel }}^{2}(3,841) p=(292)<0,005$.

Kesimpulan yang dapat di ambil adalah pengetahuan, perilaku, dukungan keluarga adalah faktor yang berhubungan dengan POMP filariasis dan yang tidak berhubungan adalah ketersediaan obat.
\end{abstract}

Kata kunci : POMP Filariasis, pengetahuan, perilaku, distribusi obat, dukungan keluarga

\begin{abstract}
Filariasis or elephantiasis or in Indonesian language known as elephantiasis disease is a disease caused by filarial worm infections that live in lymphatic channels and are transmitted by various species of mosquitoes.

The type of research used was the Cross Sectional Study design, with a sample size of 257 determined by proportional random sampling method, which was randomly drawn from each village determined, in Buntumondong village 82 samples, Langda village 72 samples, Pasui village 102 samples. Data is obtained from the Health Office.

Processing data using a computerized system with Chi-Square analysis. Chi-Square test results found that the factors that had a significant relationship with filariasis POMP to
\end{abstract}


decrease the prevalence of microfilariae were knowledge (X2 count $(5,131)>X 2$ table $(3,841)$ or value $p=(0,23)<0,05$, behavior (X2 count) $(4,046)>X 2$ table $(3,841) p=(0,44)$ $<0,05$ family support $(X 2$ count $(4,366) X 2$ table $(3,841) p=(0,73)<0,005$, which is not related to the availability of drug X2 count $(1,111)>X 2$ table $(3,841) p=(292)<0,005$.

Conclusions that can be taken are knowledge, behavior, family support is a factor associated with POMP filariasis and what is not related is the availability of drugs.

Keywords: Filariasis POMP, knowledge, behavior, drug distribution, family support

\section{PENDAHULUAN}

Filariasis atau elephantiasis atau yang dalam bahasa Indonesia dikenal sebagai penyakit kaki gajah, dan di beberapa daerah menyebutnya untut adalah penyakit yang disebabkan karena infeksi cacing filaria

Penyakit kaki gajah disebabkan oleh cacing dari kelompok nematoda, yaitu Wucheraria bancrofti, Brugia malayi dan Brugia timori (Sudomo 1990; Sahat, Ompusunggu et al. 2008). Ketiga jenis cacing tersebut menyebabkan penyakit kaki gajah dengan cara penularan dan gejala klinis, serta pengobatan yang sama. Cacing betina akan menghasilkan (melahirkan) larva, disebut mikrofilaria, yang akan bermigrasi kedalam sistem peredaran darah. Penyakit kaki gajah terutama disebabkan karena adanya cacing dewasa yang hidup di saluran getah bening. Cacing tersebut akan merusak saluran getah bening yang mengakibatkan cairan getah bening tidak dapat tersalurkan dengan baik sehingga menyebabkan pembengkakan pada tungkai dan lengan. Cacing dewasa mampu bertahan hidup selama 5-7 tahun di dalam kelenjar getah bening (Juriastuti, Kartika et al. 2010).

Data WHO menunjukkan bahwa di dunia terdapat 1,34 Trilyun dari jumlah penduduk di dunia yang berada di lebih dari 81 negara berisiko tertular filariasis, dan lebih dari 120 juta yang terinfeksi dengan farasit cacing limfatik filaria negara-negara tersebut berada di Asia dan fasifik barat. diantaranya tinggal di Asia Tenggara dan di Indonesia menjadi negara dengan kasus filariasis yang paling tinggi (WHO 2011)

Diperkirakan lebih dari 120 juta orang diantaranya sudah terinfeksi dengan 43 juta orang sudah menunjukkan gejala klinis berupa pembengkakan anggota tubuh di kaki atau lengan (Lymphoedema) atau anggota tubuh lainnyaPenyakit ini tersebar luas terutama di pedesaan, dapat menyerang semua golongan umur baik anak-anak maupun dewasa, lakilaki dan perempuan. (CDC 2010).

Penyakit kaki gajah merupakan salah satu penyakit di daerah tropis dan sub tropis yang sebelumnya terabaikan. Mengingat penyebaran yang sangat luas di Indonesia maka bila tidak ditangani dengan baik dapat menyebabkan kecacatan dan stigma psikososial yang berdampak pada penurunan produktivitas penderita, beban keluarga dan kerugian ekonomi yang besar bagi negara. Oleh karena itu penyakit kaki gajah ini telah menjadi salah satu penyakit menular yang diprioritaskan untuk dieliminasi. Di tingkat global, program eliminasi fllariasis telah dicanangkan sejak 1999, dan WHO terus menggerakkan program eliminasi ini di negara endemis, termasuk Indonesia

Filariasis atau elephantiasis atau penyakit kaki gajah, adalah penyakit yang disebabkan infeksi cacing filaria yang ditularkan melalui gigitan nyamuk, Penyakit ini tersebar luas di pedesaan dan perkotaan. Dapat dan menyerang semua golongan tanpa mengenal usia dan jenis kelamin.

Penyakit kaki gajah merupakan salah satu penyakit yang sebelumnya terabaikan. Dapat menyebabkan kecacatan, stigma, psikososial dan penurunan produktivitas penderitanya dan lingkungannya. Diperkirakan kerugian ekonomi mencapai 43 trilyun rupiah (Kementerian Kesehatan, 2009).

Berbagai akibat yang ditimbulkan oleh penyakit kaki gajah (Filariasis) selain Penyakit ini dapat menyebabkan kecacatan, stigma sosial, hambatan psikososial dan penurunan produktivitas kerja penderita, keluarga dan masyarakat sehingga menimbulkan kerugian 
ekonomi besar. Konsekwensi dari akibat tersebut, saat ini penyakit kaki gajah telah menjadi salah satu penyakit yang diprioritaskan untuk dieliminasi, atas prakarsa WHO sejak 1999, pada tahun 2000 diperkuat dengan keputusan WHO dengan mendeklarasikan "The Global Goal of Elimination of Lymphatic Filariasis as a Public Health Problem by the Year 2020". Indonesia sepakat untuk memberantas filariasis sebagai bagian dari eliminasi filariasis global.

Hasil laporan kasus klinis kronis filariasis dari kabupaten/kota yang ditindak lanjuti dengan survey endemisitas filariasis, sampai dengan tahun 2009 terdapat 337 kabupaten/kota endemis dan 135 kabupaten/kota non endemis.(Kemenkes 2010).

Daerah endemis filariasis tersebar luas di daerah tropis dan subtropis diseluruh dunia termasuk didalamnya Asia, Afrika, Cina, Pasifik dan sebagian Amerika. Di Indonesia kasus filariasis telah dilaporkan terjadi di berbagai daerah antara lain di Sumatera Selatan, Bangka Belitung, Papua, Kalimantan Timur, Jawa Tengah, Tangerang, dan lebih dari 17 Kabupaten di Jawa Barat. Filariasis limfatik disebabkan oleh 3 spesies utama cacing filaria yaitu Wuchereria bancrofti, Brugia malayi dan Brugia timori Wuchereria bancrofti dan. Brugia Timori tidak memerlukan hewan sebagai reservoir. Brugia malayi diketahui bersifat zoonosis karena dapat ditularkan dari hewan ke manusia atau dari manusia ke manusia melalui vektor nyamuk. Diduga lebih dari 77 spesies nyamuk dari genus Anopheles, Aedes, Culex dan Mansonia dapat mendukung perkembangan cacing filaria.

Kasus filariasis di Sulawesi Selatan tercatat sebanyak 135 penderita kronis yang tersebar pada 16 Kabupaten/Kota yakni; Kabupaten Gowa, Maros, Barru, Sidrap, Luwu Utara, luwu Timur, Bone, Makassar, Takalar, Enrekang, Jeneponto, Pare-pare, Wajo, Pangkep, Pinrang, dan Bulukumba. Hasil survey darah jari dan menetapkan Kabupaten. Sidrap, Kabupaten Enrekang, Kabupaten Luwu Timur dan Kabupaten Pangkep sebagai daerah endemis filariasis dengan mikrorofilaria rate (Mf rate) $>1 \%$ dan telah mengadakan pengobatan massal filariasis.(Dinkes 2012)

Kabupaten Enrekang terhitung sejak tahun 2006 telah dilakukan Pemberian Obat Massal Pencegahan (POMP) Filariasis, berdasarkan ketentuan digunakan obat Dietyl Carbamazine Citrate (DEC) $6 \mathrm{mg} / \mathrm{kg}$ berat badan yang dikombinasikan dengan albendazole 400mg sekali setahun dan dilakukan selama 5 tahun (Kemenkes 2008). Cakupan penduduk minum obat selama 5 kali berturut-turut sebesar $86 \%$, dan pada pengobatan massal tersebut penurunan prevalensi rate dapat diturunkan dari 1,9\% menjadi $0 \%$ berdasarkan hasil evaluasi survei darah jari (SDJ) dan free test tahun 2012. Sedangkan dalam pelaksanaan Transmission Asessment Survey (TAS) dengan critical cut off 18 hanya ditemukan 1 positif yang berarti tidak melampaui critical cut off sehingga dapat dinyatakan bebas endemis filariasis(Kemenkes 2008).

Pertimbangan tersebut di atas menjadi alasan bagi peneliti untuk melakukan penelitian tentang dukungan masyarakat terhadap perlaksaaan (pemberian obat massal pencegahan) POMP filariasis yang menunjang keberhasilan dalam menurunkan prevalensi mikrofilaria rate dengan thema faktor yang berhubungan dengan pemberian obat massal pencegahan (POMP) filariasis terhadap penurunan prevalensi mikrofilaria pasca pengobatan tahun ke 5 di Kecamatan Buntu Batu Kabupaten Enrekang.

\section{METODE PENELITIAN}

Jenis penelitian yang digunakan dalam penelitian observasional dengan rancanganCross Sectional Study, yang dilakukan secara bersamaan dengan tujuan untuk mengetahui faktor yang berhubungan dengan POMP filariasis terhadap penurunan prevalensi mikrofilaria pasca pengobatan tahun ke 5 di Kecamatan Buntu Batu Kabupaten Enrekang.

Populasi dalam penelitian ini adalah masyarakat pada wilayah dengan kasus kronis atau secara mikroscofis menderita filariasis yang terdapat di Desa Buntu Mandong, Desa Langda,dan Desa Pasui dengan total penduduk sebanyak 5513 jiwa. Sampel dalam penelitian ini adalah Sebagian dari masyarakat yang tinggal di Desa Buntu Mandong,Desa Langda,dan Desa Pasui. Yang Ditentukan dengan menggunakan tabel sampling pada 
tingkat kesalahan 10\% sehingga ditemukan sampel sebanyak 257 (Dr.Sugiyono 2011).

Penentuan besar sampel menggunakan metode proportional Random sampling yaitu mengambil secara acak dari masing-masing desa yang sudah ditentukan sbb: Desa Buntu mandong 82 orang, Desa langda72 orang, Desa Pasui 102 orang.

\section{HASIL PENELITIAN}

\section{Analisis Univariat}

Tabel 1

Distribusi Jenis Kelamin Responden di Kecamatan Buntu Batu Kabupaten Enrekang

\begin{tabular}{|c|c|c|}
\hline Jenis kelamin & $\mathrm{n}$ & Persentase \\
\hline Laki-laki & 144 & 44,4 \\
Perempuan & 143 & 55,6 \\
\hline Jumlah & 257 & 100,0 \\
\hline
\end{tabular}

Tabel 1 Menunjukan bahwa dari 257 jumlah responden terdapat kelompok Jenis Kelamin Laki-laki sebanyak 44,4\%, dan Perempuan sebanyak 55,6\%

Tabel 2

Distribusi kelompok Umur Responden di Kecamatan Buntu Batu Kabupaten Enrekang

\begin{tabular}{|c|c|c|}
\hline Umur & $\mathrm{n}$ & Persentase \\
\hline $85-79$ & 7 & 2,7 \\
$78-71$ & 4 & 1,6 \\
$70-63$ & 3 & 1,2 \\
$62-55$ & 22 & 8,6 \\
$54-47$ & 25 & 9,7 \\
$46-39$ & 60 & 23,3 \\
$38-31$ & 45 & 17,5 \\
$30-23$ & 62 & 24,1 \\
$22-17$ & 29 & 11,3 \\
\hline Jumlah & 257 & 100,0 \\
\hline
\end{tabular}

Tabel 2 Menunjukkan bahwa dari 257 responden terdapat kelompok umur tertinggi 8579 sebanyak $2,7 \%$ dan terendah $22-17$ sebanyak $11,3 \%$.

Tabel 3

Distribusi Jenis pekerjaan Responden di Kecamatan Buntu Batu KabupatenEnrekang

\begin{tabular}{|c|c|c|}
\hline Pekerjaan & $\mathrm{n}$ & Persentase \\
\hline Petani & 94 & 36,6 \\
URT & 125 & 48,6 \\
Wiraswasta & 12 & 4,7 \\
PNS & 26 & 10,1 \\
\hline Jumlah & 257 & 100,0 \\
\hline
\end{tabular}

Tabel 3 Menunjukan bahwa dari 257 jumlah responden terdapat kelompok pekerjaan Petani sebanyak $36,6 \%$, URT sebanyak $48,6 \%$, Wiraswasta sebanyak $4,7 \%$. Dan PNS sebanyak $10,1 \%$. 
Tabel 4

Distribusi Jenis pendidikan Responden di Kecamatan Buntu Batu Kabupaten Enrekang

\begin{tabular}{|c|c|c|}
\hline Pendidikan & $\mathrm{n}$ & Persentase \\
\hline SD & 35 & 13,6 \\
SMP & 85 & 33,1 \\
SMA & 110 & 42,8 \\
S1 & 27 & 10,5 \\
\hline Jumlah & 257 & 100,0 \\
\hline
\end{tabular}

Tabel 4 Menunjukan bahwa dari 257 jumlah responden terdapat kelompok pendidikan SD sebanyak $13,6 \%$, SMP sebanyak $13,1 \%$, SMA sebanyak $42,8 \%$ dan S1 sebanyak $10,5 \%$

Tabel 5

Distribusi Pengetahuan Responden terhadap POMP Filariasis di Kecamatan Buntu Batu Kabupaten Enrekang

\begin{tabular}{|c|c|c|}
\hline Pengetahuan & $\mathrm{n}$ & Persentase \\
\hline Kurang & 58 & 22,6 \\
cukup & 199 & 77,4 \\
\hline Jumlah & 257 & 100,0 \\
\hline
\end{tabular}

Tabel 5 Menunjukan bahwa dari 257 jumlah responden terdapat pengetahuan kurang sebanyak $22,6 \%$ dan cukup sebanyak $77,4 \%$.

Tabel 6

Distribusi perilaku Responden terhadap POMP filariasis di Kecamatan Buntu Batu Kabupaten Enrekang

\begin{tabular}{|c|c|c|}
\hline Perilaku & $\mathrm{n}$ & Persentase \\
\hline Tidak melaksanakan & 172 & 66,9 \\
Melaksanakan & 85 & 33,1 \\
\hline Jumlah & 257 & 100,0 \\
\hline
\end{tabular}

Tabel 6 Menunjukkan bahwa dari 257 jumlah responden terdapat perilaku tidak melaksanakan sebanyak $66,9 \%$ dan yang melaksanakan sebanyak $33,1 \%$

Tabel 7

Distribusi Obat Responden terhadap POMP Filariasis di Kecamatan Buntu Batu Kabupaten Enrekang

\begin{tabular}{|c|c|c|}
\hline Distribusi obat & $\mathrm{n}$ & Persentase \\
\hline Kurang & 127 & 49,4 \\
cukup & 130 & 50,6 \\
\hline Jumlah & 257 & 100,0 \\
\hline
\end{tabular}

Tabel 7 menunjukkan bahwa dari 257 responden distribusi obat kurang sebanyak 49,4\% dan cukup sebanyak 50,6\%

Tabel 8

Distribusi dukungan keluarga responden terhadap POMP filariasis di Kecamatan Buntu Batu Kabupaten Enrekang

\begin{tabular}{|c|c|c|}
\hline Dukungan keluarga & $\mathrm{n}$ & Presentase \\
\hline Tidak mendukung & 194 & 75,5 \\
Mendukung & 63 & 24,5 \\
\hline Jumlah & 257 & 100,0 \\
\hline & & \\
\hline
\end{tabular}

Tabel 8 Menunjukkan bahwa dari 257 responden dukungan keluarga terhadap POMP filariasis yang tidak mendukung sebanyak $75,5 \%$ dan yang mendukung sebanyak $24,5 \%$ 


\section{Analisis Bivariat}

a. Hubungan pengetahuan dengan POMP filariasis

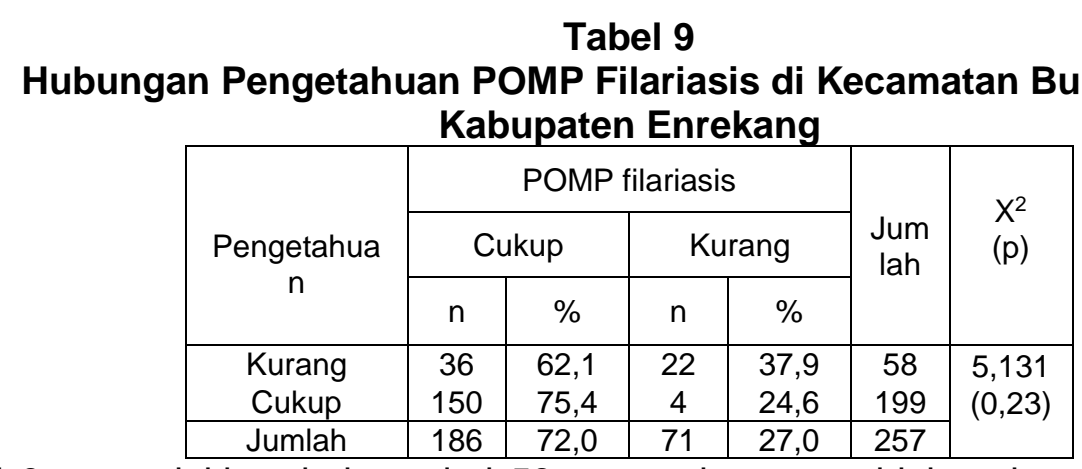

Tabel 9 menunjukkan bahwa dari 58 responden yang tidak tahu dan patuh terhadap POMP filariasis sebanyak $62,1 \%$ dan yang tidak tahu dan tidak patuh terhadap POMP filariasis sebanyak $37,9 \%$, tetapi dari 199 responden yang tahu dan patuh terhadap POMP filariasis sebanyak $75,4 \%$ dan yang tahu dan tidak melaksanakan sebanyak $24,6 \%$

Hasil analisis statistik diperoleh nilai $X^{2}$ hitung $(5,131)>X^{2}$ tabel $(3,841)$ atau nilai $p=(0,023)<$ 0,05 ini berarti ada hubungan pengetahuan dengan POMP filariasis

\section{b. Hubungan perilaku dengan POMP filariasis}

\section{Tabel 10}

Hubungan Perilaku dengan POMP Filariasis di Kecamatan Buntu Batu Kabupaten Enrekang

\begin{tabular}{|c|c|c|c|c|c|c|}
\hline \multirow{3}{*}{ Perilaku } & \multicolumn{4}{|c|}{ POMP filariasis } & \multirow{3}{*}{$\begin{array}{c}\text { Juml } \\
\text { ah }\end{array}$} & \multirow{3}{*}{$\begin{array}{l}X^{2} \\
(p)\end{array}$} \\
\hline & \multicolumn{2}{|c|}{ Cukup } & \multicolumn{2}{|c|}{ Kurang } & & \\
\hline & $\mathrm{n}$ & $\%$ & $\mathrm{~N}$ & $\%$ & & \\
\hline Tidak & & & & & & \\
\hline $\begin{array}{c}\text { Melaksanak } \\
\text { an }\end{array}$ & 117 & 68,0 & 55 & 32,0 & 172 & 4,046 \\
\hline $\begin{array}{c}\text { Melaksanak } \\
\text { an }\end{array}$ & 68 & 80,0 & 17 & 20,0 & 85 & \\
\hline Jumlah & 185 & 72,0 & 72 & 28,0 & 257 & \\
\hline
\end{tabular}

Tabel 10 menunjukkan bahwa dari 172 responden yang tidak melaksanakan dan cukup sebanyak $68,0 \%$,dan kurang sebanyak $32,0 \%$ tetapi dari 85 responden yang melaksanakan dan cukup sebanyak $80,0 \%$ dan kurang sebanyak 20,0\%.

Hasil analisis statistik diperoleh nilai $X^{2}{ }_{\text {hitung }}(4,046)>X^{2}$ tabel $(3,841)$ atau nilai $p=(, 0,044)<$ 0,05 ini berarti ada hubungan perilaku dengan POMP filariasis

\section{c. Hubungan Distribusi Obat dengan POMP filariasis}

\section{Tabel 11}

Hubungan Distribusi Obat dengan POMP Filariasis di Kecamatan Buntu Batu Kabupaten Enrekang

\begin{tabular}{|c|c|c|c|c|c|c|}
\hline \multirow{2}{*}{$\begin{array}{c}\text { Distribusi } \\
\text { obat }\end{array}$} & \multicolumn{4}{|c|}{ POMP filariasis } & \multirow{4}{*}{} & \multirow{2}{*}{$\begin{array}{c}\mathrm{X}^{2} \\
(\mathrm{p})\end{array}$} \\
\cline { 2 - 5 } & \multicolumn{2}{|c|}{ Cukup } & \multicolumn{2}{|c|}{ Kurang } & Jumlah & \\
\cline { 2 - 5 } & $\mathrm{n}$ & $\%$ & $\mathrm{n}$ & $\%$ & & \\
\hline Cukup & 97 & 69,3 & 43 & 30,7 & 140 & 1,111 \\
Kurang & 88 & 75,2 & 29 & 24,8 & 117 & $(292)$ \\
\hline Jumlah & 185 & 72,0 & 72 & 28,0 & 257 & \\
\hline & & & & & & \\
\hline
\end{tabular}


Tabel 11 menunjukkan bahwa dari 140 responden yang Distribusi obat cukup sebanyak $69,3 \%$,dan kurang sebanyak 30,7\% tetapi dari 117 responden Distribusi obat cukup sebanyak $75.2 \%$ dan kurang sebanyak $24,8 \%$.

Hasil analisis statistik diperoleh nilai $X^{2}$ nitung $(1,111)>X^{2}$ tabel $(3,841)$ atau nilai $p=(0,292)<$ 0,05 ini berarti tidak ada hubungan Distribusi obat dengan POMP filariasis.

\section{d. Hubungan Dukungan keluarga dengan POMP filariasis}

\section{Tabel 12 \\ Hubungan Dukungan Keluarga dengan POMP Filariasis di Kecamatan Buntu Batu Kabupaten Enrekang}

\begin{tabular}{|c|c|c|c|c|c|c|}
\hline \multirow{2}{*}{$\begin{array}{c}\text { Dukungan } \\
\text { keluarga }\end{array}$} & \multicolumn{4}{|c|}{ POMP filariasis } & \multirow{4}{*}{$\begin{array}{c}\mathrm{X}^{2} \\
(\mathrm{p})\end{array}$} \\
\cline { 2 - 6 } & \multicolumn{2}{|c|}{ Cukup } & \multicolumn{2}{|c|}{ Kurang } & \multirow{2}{*}{ Jumlah } & \\
\cline { 2 - 6 } & $\mathrm{n}$ & $\%$ & $\mathrm{n}$ & $\%$ & & \\
\hline Cukup & 140 & 69,0 & 63 & 31,0 & 203 & 4,366 \\
Kurang & 45 & 83,3 & 9 & 16,7 & 54 & $(0,37)$ \\
\hline Jumlah & 185 & 72,0 & 72 & 28,0 & 257 & \\
\hline & & & & & & \\
\hline
\end{tabular}

Tabel 12 menunjukkan bahwa dari 203 responden dukungan keluarga cukup sebanyak $69,0 \%$,dan kurang sebanyak $31,0 \%$ tetapi dari 54 responden Dukungan keluarga cukup sebanyak $83,3 \%$ dan kurang sebanyak $28,0 \%$.

Hasil analisis statistik diperoleh nilai $X^{2}$ nitung $(4,366)>X^{2}$ tabel $(3,841)$ atau nilai $p=(0,073)<$ 0,05 ini berarti ada hubungan Dukungan keluarga dengan POMP filariasis.

\section{PEMBAHASAN}

\section{Hubungan pengetahuan dengan POMP filariasis terhadap penurunan prevalensi} Mikrofilaria

Pengetahuan merupakan hasil dari tahu dan ini terjadi setelah seseorang melakukan penginderaan terhadap suatu objek tertentu. Penginderaan tersebut terjadi melalui panca indera manusia: seperti penglihatan, pendengaran, penciuman, rasa dan raba. Pengetahuan manusia sebagian besarnya diperoleh melalui mata dan telinga. Pengetahuan merupakan domain yang penting terbentuknya perilaku seseorang (Notoatmojo.S 2005)

Responden dalam penelitian ini sebanyak 58 responden yang tidak tahu dan patuh terhadap POMP filariasis sebanyak $62,1 \%$ dan yang tidak tahu dan tidak patuh terhadap POMP filariasis sebanyak 37,9\%, tetapi dari 199 responden yang tahu dan patuh terhadap POMP filariasis sebanyak $75,4 \%$ dan yang tahu dan tidak melaksanakan sebanyak $24,6 \%$

Hasil analisis statistik diperoleh nilai X2 hitung $(5,131)>$ X2 tabel $(3,841)$ atau nilai $p=(0,023)<0,05$ ini berarti ada hubungan pengetahuan dengan POMP filariasis.

Pengetahuan masyarakat terhadap pemberian obat massal pencegahan filariasis terkait dengan ketelatenan minum obat sehingga memberi kontribusi masyarakat dalam melaksanakan program minum obat secara massal di kecamatan Buntu Batu kabupaten Enrekang. Penelitian ini sejalan dengan penelitian Nasrin Fakultas kesehatan masyarakat Universitas Diponegoro yang meneliti di wilayah kerja puskesmas dan dinas kesehatan Bangka Barat dengan penelitian pengetahuan masyarakat dengan pemberian obat massal pencegahan (POMP) filariasis, dimana Hasil analisis statistik diperoleh nilai X2 hitung $(3,924)>X 2$ tabel $(3,841)$ atau nilai $p=(0,001)<0,05$ ini berarti ada hubungan pengetahuan dengan POMP filariasis. Besarnya angka pengetahuan masyarakat terhadap POMP filariasis sehingga pengobatan Massal berhasil di kecamatan Buntu Batu kabupaten Enrekang 


\section{Hubungan perilaku dengan POMP filariasis terhadap penurunan prevalensi mikrofilaria}

Perilaku adalah tanggapan atau reaksi individu terhadap rangsangan atau lingkungan. Perilaku sebagai suatu proses interaksi individu dengan lingkunganya sebagai menifestasi hayati bahwa dia adalah mahluk hidup (Notoatmojo.S 2005)

Dengan perilaku masyarakat yang tekun minum obat massal pencegahan (POMP) filariasis, dan mereka pun mengetahui akan pentingnya minum obat massal pencegahan (POMP) filariasis. sehinggah keberhasilan penurunan prevalensi mikrofilaria di tunjang dari segi perilaku masyarakat yang patuh minum obat massal yang diberikan 1 kali setiap tahun selama 5 tahun berturut-turut.

Dari 172 responden yang berperilaku cukup sebanyak 68,0\%,dan kurang sebanyak $32,0 \%$ tetapi dari 85 responden yang berperilaku cukup sebanyak $80,0 \%$ dan kurang sebanyak 20,0\%.

Hasil analisis statistik diperoleh nilai X2 hitung $(4,046)>$ X2 tabel $(3,841)$ atau nilai $\mathrm{p}=(0,044)<0,05$ ini berarti ada hubungan perilaku dengan POMP filariasis.

Penelitian ini sejalan dengan Viana fakultas kesehatan masyarakat universitas sumatra utara di Puskesmas Kusuma Bangsa berlokasi di Kota Pekalongan Kecamatan Pekalongan Utara dengan penelitian perilaku masyarakat dengan pemberian obat massal pencegahan (POMP) filariasis, dimana Hasil analisis statistik diperoleh nilai X2 hitung $(7,038)>X 2$ tabel $(3,841)$ atau nilai $p=(0,009)<0,05$ ini berarti ada hubungan perilaku dengan POMP filariasis.

\section{Hubungan Distribusi obat dengan POMP filariasis terhadap penurunan prevalensi mikrofilaria}

Pendistribusian obat pada saat pengobatan massal agar mencapai seluruh sasaran dan mendapatkan obat sesuai dengan dosis yang telah ditentukan, pelaksaanaan pengobatan massal dilaksanakan secara serentak di wilayah yang telah dinyatakan endemis dengan angka mikrofilaria rate (Mf rate) kurang dari $1 \%$.

Dari 140 responden yang dapat menerima obat dari distribusi obat cukup sebanyak 69,3\%,dan kurang sebanyak 30,7\% tetapi dari 117 responden distribusi obat cukup sebanyak $75.2 \%$ dan kurang sebanyak $24,8 \%$.

Hasil analisis statistik diperoleh nilai X2 hitung $(1,111)>X 2$ tabel $(3,841)$ atau nilai $\mathrm{p}=(0,292)<0,05$ ini berarti tidak ada hubungan distribusi obat dengan POMP filariasis.

Distribusi obat tidak berhubungan / berkolerasi dengan POMP karena responden tidak berperan secara langsung terhadap pendistribusian obat melainkan tanggung jawab petugas kesehatan, sehingga distribusi obat secara statistik tidak berhubungan dengan POMP filariasis oleh masyarakat.

\section{Hubungan dukungan keluarga dengan POMP filariasis terhadap penurunan prevalensi mikrofilaria}

Dukungan keluarga adalah sikap, tindakan dan penerimaan keluarga terhadap anggotanya. Anggota keluarga memandang bahwa orang yang bersifat mendukung selalu siap memberikan pertolongan dan bantuan jika diperlukan (Friedman, 2003).

Keluarga adalah orang terdekat yang selalu mendukung untuk anggota keluarganya. Dengan adanya dukungan dari keluarga maka program pemberian obat massal pencegahan filariasis sukses di tinjau dari dukungan keluarga.

Dengan adanya dukungan dari keluarga kesadaran untuk minum obat pencegahan filariasis akan meningkat karna anggota keluarga termotifasi untuk minum obat,disamping mengetahui manfaat obat pencegahan filariasis dan kemauan dari diri sendiri sehinggah prevalensi mikrofilaria dapat diturunkan di kecamatan Buntu Batu Kabupaten Enrekang

Dari 203 responden dukungan keluarga cukup sebanyak 69,0\%,dan kurang sebanyak $31,0 \%$ tetapi dari 54 responden Dukungan keluarga cukup sebanyak $83,3 \%$ dan kurang sebanyak $28,0 \%$. 
Hasil analisis statistik diperoleh nilai X2 hitung $(4,366)>X 2$ tabel $(3,841)$ atau nilai $\mathrm{p}=(0,073)<0,05$ ini berarti ada hubungan Dukungan keluarga dengan POMP filariasis.(Drs. Sukardi Pangade 2013)

\section{KESIMPULAN}

Berdasarkan hasil penelitian tentang faktor yang berhubungan dengan POMP filariasis maka di peroleh kesimpulan bahwa ada hubungan secara signifikan antara va riable pengetahuan, perilaku, dan dukunga $n$ keluarga terhadap POMP filariasis. Sedangkan variable distribusi oba ttidak memiliki hubungan dengan POMP filariasis.

\section{DAFTAR PUSTAKA}

CDC (2010). "Policy Brief: Lymphatic Filariasis (LF)." CDC, Center for Global Health, Division of Parasitic Diseases and Malaria,www.cdc.gov/parasites/lymphaticfilariasis

Chandra, G. (2008). "Nature limits filarial transmission." BioMed Central1:13: 1 - 6.

Charles H Washington, Jeanne Radday, et al. (2004). "Spatial clustering of filarial transmission before and after a Mass Drug Administration in a setting of low infection prevalence." Filaria Journal 3:3: 1 - 14.

Dinkes (2012). Laporan Tahun. Makassar, Dinas Kesehatan Provinsi Sulawesi Selatan.

Dr.Sugiyono, P. (2011). Statistika untuk penelitian. Bandung, Alfabeta.

Drs. Sukardi Pangade, S., Mkes. Yusrianto, SKM.,M.Kes (2013). panduan penulisan skripsi universitas Indonesia Timur. Makassar.

Effendy,(2002) konsep dukungan keluarga. surabaya,. Citramedia

Johannaerhell, A. (2002). Epidemiological facets of lymphtic filariasis as revealet by the use of anti-filarial lgG4.

Juriastuti, P., M. Kartika, et al. (2010). "Faktor risiko kejadian filariasis di Kelurahan Jati Sampurna." Makarara Kesehatan 14: 31 - 36.

Kemenkes, R. (2008). Pedoman program eliminasi filariasis di Indonesia. Jakarta, Direktorat Jenderal PP dan PL

Kemenkes, R. (2008). Pedoman program eliminasi filariasis di Indonesia. Jakarta, Dirjen PP dan PL.

Kemenkes, R. (2010). Rencana Nasional Program Akselerasi Eliminasi Filariasis di Indonesia. Jakarta, Subdit filariasis dan schistosomiasis Direktorat P2B2 Ditjen PP \& PL.

Notoatmojo.S (2005). pemberdayaan masyarakat dalam promosi kesehatan,teori, dan aplikasi.

Sahat, M., Ompusunggu, et al. (2008). "Endemisitas Filariasis dengan Lama Pengobatan Massal Berbeda." Majalah Kedokteran Indonesia 58 No. 11: 413-420.

Sudomo, M. (1990). "Aspek Epidemiologi filariasis yang berhubungan dengan pemberantasannya." Cermin Dunia Kedokteran 64: 11 - 14. 
Sumanto, D. and S. S. Dewib (2005). "Survei Kejadian Filariasis Pada Masyarakat Desa Tawangrejo Kundaran Blora." Jurnal Litbang Universitas Muhammadiyah Semarang: 47 - 53.

Shochib (2004) " hubungan Aspek dukungan keluarga ; Jakarta PT. Alpabeta

WHO (2003). The Global Elimination of Lymphatic Filariasis The Story of Egypt. Geneva, Switzerland, 20, Avenue ppia, CH - 1211 Geneva, Switzerland Tel.: +41 22.791.21.11 website: http://www.who.int.

WHO (2011). Monitoring and epidemiological assessment of mass drug administration in the global programme to eliminate lymphatic fi lariasis: a manual for national elimination programmes. W. L. C.-i.-P. Data. Geneva, Publications of the World Health Organization are available on the WHO web site (www.who.int) or can be purchased from WHO Press, World Health Organization, 20 Avenue Appia, 1211 Geneva 27, Switzerland (tel.: +41 22791 3264; fax: +41 22791 4857; e-mail: bookorders@who.int). 